\title{
Política social e racismo como desafios para historiadores da educação
}

\author{
Social policy and racism as challenges for \\ educational bistorians
}

\author{
Marcos Cezar de Freitas \\ Professor da Pontifícia Universidade Católica de São Paulo \\ Rua Sete de Setembro, 407 Jardim S. Rita de Cassia \\ 12914-080 Bragança Paulista — SP Brasil \\ mcezar@pucsp.br
}

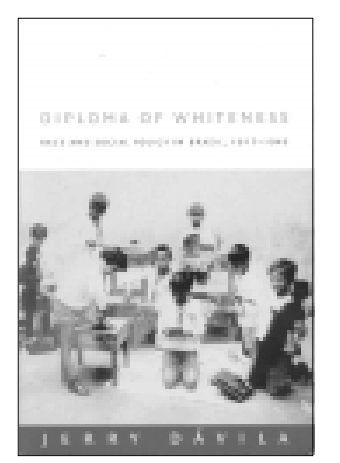

Jerry Dávila Diploma of whiteness: race and social policy in Brazil, 1917-1945 Duke University Press, Durham \& London, 2003, 292 p.
$\mathrm{O}$ livro de Jerry Dávila convida o leitor a retomar uma série de reformas levadas a efeito no campo educacional de 1917 a 1935 , período de grande efervescência política, no qual as iniciativas governamentais direcionadas à escola não deixavam de significar, ao mesmo tempo, um conjunto abrangente de medidas também relacionadas à saúde pública e às políticas sociais em sentido amplo.

$\mathrm{Na}$ trama narrada por Dávila, alguns personagens foram protagonistas de ações com maior visibilidade e impacto social, e alguns 'lugares políticos' são retratados como palcos privilegiados dessas performances. Entre os atores encontramos Anísio Teixeira, os ministros Francisco Campos e Gustavo Capanema, intelectuais católicos, Teixeira de Freitas, Roquette-Pinto e vários representantes da pesquisa 'psicométrica' na escola, destacadamente Lourenço Filho. Entre os 'lugares políticos' encontramos o Ministério da Educação e Saúde, o Colégio D. Pedro II e o Instituto de Educação do Distrito Federal, só para citar os de maior repercussão e mais decisivos na construção da argumentação do autor.

Nos seis capítulos do livro os problemas sociais relacionados às questões raciais são tratados como decorrência daquilo que, na ótica do autor, é uma constante na sociedade brasileira: a renovação de procedimentos com os quais a distância entre raças se acentua, mesmo quando é possível verificar a expansão do acesso de negros e mulatos às instituições públicas, principalmente a escola. O Brasil teria a peculiaridade de renovar, ao infinito, procedimentos e ideologias de corte eugênico, com os quais a confrontação entre raças seria 'dispensável' mediante a institucionalização de algumas políticas responsáveis pelo 'branqueamento' da sociedade. Este branqueamento seria a única alternativa aceita pelas elites, opinião comungada com quase todos os intelectuais que lidaram com os temas educação e saúde no período. O ensino secundário, por exemplo, teria sido uma instituição 'branqueadora', e os processos pelos quais consolidou-se um modelo de recrutamento e formação de professores teriam culminado com a hegemonia de um 'tipo social': o indivíduo branco de classe média.

O livro em questão expõe, com argumentação fluente e o tempo todo direta, as relações visíveis entre reformas educacionais, organização de departamentos de estatística, ações ministeriais, ensino secundário e mobilidade social com as agruras decorrentes das questões 
raciais em um Brasil que se modernizava - ainda que, a partir de 1937, lançando mão do expediente de uma ditadura.

Um dos argumentos básicos do autor consiste em reconhecer continuidades segregacionistas nos domínios das iniciativas educacionais, as quais, mesmo que inseridas em movimentos de expansão de oferta, estariam diluídas em um contexto de recrudescimento permanente da diferença de oportunidades entre brancos e negros no Brasil. Paradoxalmente, ele ressalva, os negros não teriam sido 'bloqueados' na primeira metade do século XX, recebendo das autoridades educacionais a oportunidade de participar da expansão educacional ocorrida entre 1917-1945. Todavia nos limites dessa expansão estariam contidos os próprios limites do negro na sociedade brasileira, ou seja, depositavam-se nas medidas educacionais novas estratégias de branqueamento da sociedade, então diluídas em novos padrões estéticos, em novos resultados aferidos em testes de inteligência e, principalmente, nas indicações a respeito do lugar de cada um neste país.

Um episódio, narrado logo ao início, dá a tônica da argumentação do autor. Nos 'tempos Capanema', o Colégio Notre Dame recusou a matrícula da aluna Jacyra, descendente de índios, com argumentos de corte racista. A polêmica que sucedeu à recusa é exemplar do que a trama quer mostrar. Por um lado, vozes como a de Sobral Pinto defendiam as irmãs do Colégio Notre Dame da acusação de discriminação racial, com o argumento de que as mesmas atuavam com bases em um "racismo já existente" e que, diante da imposição conjuntural, não estavam interessadas em criar embaraços para os pais dos alunos. A instituição procurava 'defender' a própria criança contra a hostilidade que certamente a atingiria, decorrente da situação de ser, entre iguais, uma pessoa racialmente 'diferente'.

O episódio ensejou o espraiar de um debate a respeito da incômoda questão: o brasileiro é ou não racista?

O autor trabalha com a certeza de que o mote das políticas sociais do período era a realização de um projeto das elites. Estas tendiam a acreditar que pobres e não-brancos eram degenerados. As 'patologias' da degeneração faziam com que a escola e a escolarização fossem pensadas clinicamente, uma vez que deveriam ser associadas ao processo de cura dos males provocados pela miscigenação. Para demonstrar com fatos a plausibilidade de seu argumento, Dávila relembra uma emergente medicina 'branca', combinada com uma nova ciência social que, no bojo de ações intelectuais profissionalizadas na esfera estatal, transformavam antigas concepções sobre raça em políticas públicas, especialmente no campo educacional.

Aqui começamos a encontrar alguns problemas.

É possível que todos nós, leitores, fiquemos inquietos, no transcorrer da leitura, com a quantidade de vezes em que a análise de Dávila relaciona as práticas de 'branqueamento' levadas a efeito nas escolas do Rio de Janeiro, sob a influência da Escola Nova na ação dos educadores brasileiros. Há uma certa insistência em pontuar a relação de causa e efeito entre as 'americanofilias' de educadores brasileiros como Carneiro Leão, Anísio Teixeira e Lourenço Filho e o deslum-bramento com as práticas 
de psicometria, com as quais a inteligência educacional participava indiretamente do processo de branqueamento da sociedade. Para citar um só exemplo, o autor retira um número expressivo de conclusões a respeito do formato acadêmico do Instituto de Educação do Distrito Federal, a partir do pressuposto de que esta escola reproduzia, aqui, o que fazia o Teachers College na Columbia University. O Teachers College, na argumentação de Dávila, teria ambientado Anísio no espírito da filosofia de John Dewey, convertendo-o em um 'deweyano'.

É equivocado pensar que Anísio Teixeira montou as instituições que montou porque era discípulo de John Dewey, querendo, com isso, deixar subentendido que já se encontrava na obra de Dewey um conjunto de subsídios às práticas que, no Brasil, resultaram problemáticas. Relações de causa e efeito desta natureza não se sustentam. Basta o leitor procurar na obra de Dewey uma linha sequer em defesa da psicometria, para concluir que a relação é, por assim dizer, forçada, pois não encontrará na chamada 'matriz' nada que respalde a ação da denominada 'filial'.

Isso quer dizer que, provavelmente, as reformas de Anísio Teixeira, com todo o seu caráter espetacular comentado pelo autor e ainda que sempre proclamadas como resultado material das influências intelectuais e filosóficas do reformador, resultaram antes das tramas políticas e tensões entre grupos, situações compreensíveis somente com o olhar aproximado da própria sociedade brasileira. Para sustentar que o 'racismo à brasileira' espalhava-se na departamentalização de iniciativas originadas, não só mas também, no escolanovismo, cometese o exagero de supor a existência de 'uma' filosofia de educação norte-americana a respaldar um modelo de educação segregacionista. Nem a filosofia deweyana apoiava a separação entre brancos e negros, nem sua eventual aplicação aqui intentava orientar metodologicamente práticas classificatórias. Implicitamente, recria-se o argumento de que nossos 'sistemas de branqueamentos' eram manifestações singulares, abrasileiradas de um racismo que aqui variava em intensidade, em relação aos Estados Unidos.

O autor tem a uma 'noção de escala' que lhe cria uma dificuldade argumentativa: nosso racismo seria diferente daquele praticado nos EUA, mas para comprovar a veracidade de tal diferença argumenta, paradoxalmente, que estávamos a refletir, aqui, práticas suscitadas lá. Afirma, mais de uma vez, que não se deve comparar um país com outro, e no entanto este 'outro' é utilizado para confirmar origens de um modelo. Eis um paradoxo insolúvel na argumentação, ou seja, o próprio argumento nega o que quer confirmar e confirma o que quer negar.

O autor é bastante convincente quando sustenta que, para os educadores brasileiros, raça era um conceito menos preso à biologia e mais atinado com as metáforas do tempo. "Blackness" seria o passado (onde nos degradamos na escravidão) e "whiteness", o futuro. Alguns depoimentos de Gustavo Capanema, Lourenço Filho, Heitor Villa Lobos, Jonathas Serrano e Arthur Ramos não deixam dúvida a respeito da presença desse raciocínio 'de passagem' de uma situação à outra, em suas falas sobre a ação governamental. 
Lourenço Filho, nesse cenário, merece destaque.

O psicólogo da educação, também personagem de destaque nessa trama, é responsável pela cristalização de uma memória da psicologia no Brasil, na qual a Escola Ativa, forma 'norte-americana' da Escola Nova, seria a origem dos testes psicométricos e de aferição de inteligência baseados na idéia de medição do intelecto e teste das possibilidades do desempenho individual, após um primeiro momento de predomínio dos modelos franceses. Seus famosos Testes ABC comparecem na narrativa de Dávila como comprovação das origens intelectuais do que se fazia nas instituições educacionais brasileiras sob o impulso ora de Anísio Teixeira, ora de Gustavo Capanema, ora do próprio Lourenço Filho.

Aqui há um problema de natureza historiográfica.

Uma vez que Lourenço Filho faz de si um inaugurador das práticas mais modernas de psicologia educacional, Dávila se deixa convencer pelo argumento de que ali, no âmbito daquelas reformas, engendravase uma forma 'aggiornada' de tratar diferenças raciais à luz de novas expectativas de branqueamento (cf. Lourenço Filho, 1994).

Deve-se ressalvar que Lourenço se fez continuador de um Dewey que não existiu. $\mathrm{O}$ intelectual norte-americano não foi um dos pais da psicometria no campo da educação escolar. Lourenço Filho, quando se projeta como fonte para os estudos da história da psicologia educacional brasileira, o faz de modo a criar seu papel de 'inaugurador'. Em seus escritos menciona, com muita pressa, que os testes de inteligência já estavam em ebulição nos seus primeiros lugares de convívio intelectual - as iniciativas de Oscar Thompson na capital paulista, que, entre outros, criara o Laboratório de Psicologia Educacional para o italiano Ugo Pizzoli. Passa ao largo, também, de Manoel Bomfim, mencionando-o superficialmente e olvidando que, no Pedagogium do Rio de Janeiro, Bomfim já enfrentara o tema da aferição de inteligência chegando a resultados surpreendentes, mas nenhum associado a questões étnicas. Ou seja, Dávila embarcou na parcialidade de seus próprios personagens e recebeu delas uma impressão que não se sustenta historicamente.

Que conclusão podemos tirar? A de que os laboratórios de psicometria e os testes de inteligência têm significados diferentes conforme o contexto e o sujeito implicados na sua realização. Portanto não se trata de um conjunto de conhecimentos urdido para justificar o racismo. A justificativa do racismo com os argumentos da psicometria é fruto do jogo de tensões que só se apreende desvelando-se quem fala, com que 'armas verbais' e de que lugar. Não fosse assim, poderíamos radicalizar o anti-historicismo e afirmar que se Manoel Bomfim estivesse onde Lourenço Filho esteve os resultados seriam os mesmos, porque, a seguir a lógica de Dávila, a presença dos instrumentos é suficiente para comprovar o resultado da ação. Não há sujeito; há uma reunião de 'provas' de que a sociedade brasileira sempre esteve 'racializada'.

Mas o que fazer, então, com uma sociedade tão desigual como a brasileira, na qual o diferencial de cor tantas vezes é prova irrefutável de discrepâncias e estratificações as mais complexas? Ao problematizarmos os pressupostos de Dávila, estamos renovando o mito da 
democracia racial, ou ignorando o sofrimento concreto de milhares de pessoas? Absolutamente não.

O autor traz em seu livro as imagens, inclusive com ótima seleção fotográfica, de um processo no qual doutores e cientistas sociais tornaram a educação pública uma arena para a ação social. Esses reformadores estabeleceram uma visão de valores sociais que privilegiou o branco, a aparência de classe média, criando uma hierarquia de valores dentro da escola mediante a instalação de um espelho em que, independentemente da pessoa a se observar, a imagem refletida era a do brasileiro sonhado pelas elites: um tipo esteticamente branco.

Tais ações intra-escolares tinham continuidade, no plano macrosocial, em um conjunto paralelo de iniciativas empresariais, através das quais se demandava a 'taylorização' da mão-de-obra a ser empregada na expansão industrial em andamento, especialmente na região Sudeste e, mais especialmente ainda, na cidade de São Paulo. O autor tenta fotografar uma sociedade em processo de transformação e, ao mesmo tempo, sustentar a hipótese de que a expansão de ofertas, tanto nas escolas públicas quanto nos postos de trabalho, não deixava de exigir uma prévia transformação das crianças, dos jovens, das mulheres e dos homens em sujeitos cônscios de seus lugares na pirâmide social, topoi derivados do fenótipo de cada qual.

Romper com isso não significava quebrar a lógica de uma sociedade considerada por Dávila racializada. Ao contrário; romper com situações de origem significava 'branquear-se'. Uma das experiências mais pródigas em oferecer a chance do branqueamento estava contida na oportunidade de se passar pelo ensino secundário. Este é mostrado, na narrativa do autor, como estrutura em contínua expansão, mas também como lugar de treino de uma estreita elite cujos valores de ascensão social eram os que demandavam o branqueamento da sociedade. Dávila afirma com todas as letras: as políticas públicas, quanto ao aspecto racial, não eram neutras; elas atendiam de diversas formas as expectativas de transformação dos componentes raciais emanados das elites.

Nesse sentido, as políticas foram especialmente bem-sucedidas em criar um corpo de professores quase que exclusivamente branco, o que faz o autor indagar: "O que aconteceu com os professores negros do Rio de Janeiro?” (p. 90).

A expansão da oferta de espaços públicos não significava integração de afrodescendentes, nem as oscilações decorrentes da instabilidade política alteravam os componentes técnicos de cada instituição, de cada departamento ou de cada projeto. Se variava episodicamente a pessoa a responder por determinada iniciativa, na ótica do autor não variavam seus efeitos: distanciamento e exclusão racial. Este é o eixo argumentativo que, no meu entender, tem seu ponto alto - e não quando o autor insiste em provar o tom danoso da utilização de técnicas antropométricas na escola e nas políticas sociais, de resto tão evidente que desnecessário.

O ponto alto do livro está na recuperação da oportunidade, não perdida por Teixeira de Freitas, em organizar a estatística como ciência social e, especialmente, como ciência da educação. Este ponto alto se complementa com a feliz recuperação das considerações de Joaquim Thomaz, 
do Serviço de Antropometria, a respeito das "singularidades do homem rústico". Segundo Thomaz a história seria, ela mesma, o campo do inevitável, uma vez que a existência de brancos em situação econômica privilegiada e de negros em situação oposta, ou seja, em situação de penúria, colocaria diante dos nossos olhos uma constatação: a história teria feito do negro um componente biológico adaptável à pobreza. Eis a lógica surpreendente, que afirma: "Se assim foi é porque assim é."

O livro de Jerry Dávila expõe paradoxos impressionantes da sociedade brasileira, como a diversidade sociocultural observada no Colégio Pedro II ao momento das reformas analisadas em seu livro, em um contexto em que, como se percebe, nada favorecia a presença de tal diversidade. Mas os resultados sociais de tais paradoxos eram inócuos, o que é confirmado, por exemplo, na simultânea expansão de instituições de caráter vocacional que, rapidamente, tornaram-se instituições 'de pobres' e, portanto, 'de negros e mulatos'.

Diante de tudo o que foi apaixonadamente narrado "sem neutralidade" pelo autor, talvez seja necessário apresentar uma dificuldade sua, relativa à percepção que tem da distância entre povo e elites de uma forma geral. Não se trata absolutamente de emitir-lhe conselhos, mas de sugerir que analise mais detidamente os lugares de mobilidade social neste país. O ensino secundário, por exemplo, que ocupa lugar de relevo em sua análise, foi conquistado no transcorrer do século XX pelos segmentos mais pobres (cf. Sposito, 1992). Só que, à medida que foi conquistado, o prestígio a ele relacionado foi sendo deslocado para o ensino superior, fato que se repete na atual expansão do ensino superior e no subseqüente deslocamento de prestígio para os condomínios da pós-graduação.

O exemplo é necessário para introduzir o argumento de que a idéia de raça ocupa um lugar próprio na complexidade das relações sociais brasileiras, nas quais sofisticados mecanismos de exclusão social mantêm pobres cada vez mais pobres e ricos cada vez mais ricos. O preconceito racial é parte de um contexto de segregação geral do pobre e, assim, as instituições destinadas à pobreza 'perdem o valor' à proporção que se expandem, porque não participam de nenhum processo efetivo de desconcentração de renda e oportunidades sociais.

Em países como o Brasil, a pedagogia nunca sobreviveu sem reeditar constantemente as imagens de um 'outro rústico' a ser guindado, via educação, à condição de homem cosmopolita. Por isso, no mais das vezes, educação é aferição (antropométrica ou não) do que lhe falta e não do que já tem. Em decorrência, muitas vezes a escola tem sido um lugar de aferição porque, nela, a criança raramente ocupa o centro das atenções, e quando é lembrada desponta, nas medidas dos aplicadores de teste — não tenhamos ilusões - não como objeto central da observação; o centro está ocupado pelo próprio aferidor, que dispõe de ferramentas de estudo da escolarização como instância laboratorial, na qual estão em jogo suas hipóteses. A criança ou está ausente, ou é secundária.

O teste e a técnica, per se, não nascem instrumento do racismo. Daí ser importante perceber o momento em que determinados analistas, ao criarem seus instrumentos, criam metaforicamente também a sociedade a ser 
analisada, uma sociedade ao seu gosto, por assim dizer, antes racializada do que pobre. Quero dizer que, muitas vezes, o analista de determinadas situações históricas nas quais o componente racial se manifesta necessita, antes de investigar historicamente a situação, instalar 'seu' lugar de análise e sua 'família conceptual'.

É por isso que a argumentação ensejada pelo livro Diploma of whiteness desafia os educadores brasileiros. Em confronto com a realidade, suas assertivas provavelmente encontrariam respaldo na opinião de muitos professores, que se posicionariam como testemunhas cotidianas da epopéia de distanciamento narrada pelo autor. Mas é necessário que os analistas de temas tão complexos, quando se incumbem da responsabilidade de estudar a 'singularidade brasileira', não se movimentem dos Estados Unidos para cá, da Escola Nova para a reforma educacional brasileira, do racismo em qualquer sociedade para a forma como pobres, negros ou não, são aqui tratados, mas que façam o movimento inverso, partindo de 'dentro das relações sociais' que se quer compreender para fora, para o entorno.

Jerry Dávila termina seu instigante trabalho reportando-se à Revista Veja que circulou em dezembro de 2000, com "grandes novidades no campo da genética”. Na matéria em questão, o Laboratório de Genética da Universidade Federal de Minas Gerais oferecia argumentos que comprovariam a hipótese de Gilberto Freyre: o Brasil seria, realmente, um laboratório racial. No estudo apresentado, 60\% dos que se consideram brancos, do ponto de vista da genética seriam negros ou indígenas.

A reportagem inspirou o autor, inclusive, na escolha do título do trabalho. Mais do que isso, tornou-se uma espécie de 'estrela guia' de sua investigação sobre o tema do 'branqueamento' na sociedade brasileira. Causa alguma espécie constatar que um texto não isento da volatilidade própria desse tipo de abordagem tenha ocupado lugar decisivo na construção de seu argumento. Mas isto demanda um outro debate.

\section{REFERÊNCIAS BIBLIOGRÁFICAS}

Lourenço Filho, Manoel B.

1994

Sposito, Marília

1992
'A psicologia no Brasil'. Em Fernando de Azevedo (org.). As ciências no Brasil, vol. II. Rio de Janeiro, Editora da UFRJ, pp. 301-42.

O povo vai à escola. São Paulo, Editora Loyola.

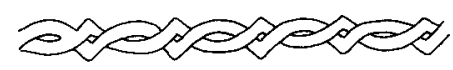

